\title{
Actinium Ac-225 Anti-PSMA Monoclonal Antibody J591
}

National Cancer Institute

\section{Source}

National Cancer Institute. Actinium Ac-225 Anti-PSMA Monoclonal Antibody 1591. NCI

Thesaurus. Code C153159.

A radioimmunoconjug ate consisting of a humanized monoclonal antibody directed against prostate specific membrane antigen (PSMA) labeled with the alpha particleemitting radioisotope actinium Ac-225, with potential antineoplastic activity. Upon administration, actinium Ac-225 anti-PSMA monoclonal antibody 5591 binds to the extracellular domain of PSMA with high affinity, thereby delivering alpha radiation to PSMA expressing cells. PSMA, a type II membrane protein expressed in all types of prostatic tissues, is often overexpressed in tumor cells. 